\title{
A RESILIÇÃO UNILATERAL NO CONTRATO DE GESTAÇÃO POR SUBSTITUIÇÃO
}

UNILATERAL RESILIENCE IN THE SUBSTITUTION MANAGEMENT CONTRACT

Mariana RUZZI ${ }^{1}$

Rosângela Aparecida Vilaça BERTONI ${ }^{2}$

ISSUE DOI: $10.21207 / 2675-0104.2018 .892$

\section{RESUMO}

Este trabalho teve por objetivo analisar a importância do desenvolvimento de regulamentação sobre a gravidez por substituição no ordenamento jurídico brasileiro, bem como a aplicação das regulamentações já existentes, e seus reflexos práticos através de aspectos dogmáticos relativos à gravidez por substituição, resoluções de cunho ético e projetos de leis. O presente trabalho estudou a relação jurídica que advém da técnica de reprodução assistida conhecida como gravidez por substituição através do direito comparado, utilizando-se da legislação e do contrato existentes em Portugal, para desta forma comprovar a importância de regulamentar através da legislação brasileira esta prática e analisar os casos de resilição unilateral no Brasil com base na legislação vigente e nas Resoluções do Conselho Federal de Medicina.

Palavras chave: gravidez por substituição; reprodução assistida; contrato; resilição unilateral;

\section{ABSTRACT}

\footnotetext{
${ }^{1}$ Discente da Faculdade de Direito de Franca/SP. Bolsista do Programa Interno de Iniciação Cientítica (PIBIC 2018-2019). Contato: marianaruzzi@hotmail.com. Currículo Lattes: http://lattes.cnpq.br/5332862359541525.

${ }^{2}$ Possui graduação em Direito pela Faculdade de Direito de Franca (1982), mestrado em Direito Empresarial pela Universidade de Franca (2002) e Especialização em Direito Registral Imobiliário pela Universidade Esade-Espanha. Tem experiência na área de Direito, com ênfase em Direito Civil e assessoria jurídica. Advogada Militante.
} 
The objective of this study was to analyze the importance of the development of regulations on surrogacy in the Brazilian legal system, as well as the application of existing regulations, and its practical reflexes through dogmatic aspects related to surrogacy, ethical resolutions and draft laws. Thus, the present study studied the legal relationship that comes from the assisted reproduction technique known as pregnancy by substitution through comparative law, using the existing legislation and contract in Portugal, in order to prove the importance of regulating through legislation this practice and to analyze the cases of unilateral resilition in Brazil based on the current legislation and the Resolutions of the Federal Council of Medicine

Keywords: surrogacy; assisted reproduction; contract; resolution of the National Medical Council $(C F M)$; unilateral resilition.

\section{INTRODUÇÃO}

O presente trabalho tem por objetivo abordar a relação jurídica que advém da técnica de reprodução assistida conhecida como gravidez por substituição e a importância de regulamentar através da legislação brasileira esta prática. ${ }^{3}$

Os avanços da bioética e do conceito de família permitiram profundas e relevantes transformações no contexto familiar, as quais afetam diretamente sua abordagem jurídica. Por exemplo, nota-se que o modelo patriarcal de família deixou de ser o único, de modo que o direito passou a regular diversas outras organizações familiares, como por exemplo a união estável.

Diante do direito ao planejamento familiar e à parentalidade, foi de suma importância o avanço da medicina em relação a reprodução assistida. Com a possibilidade desta técnica, intensificaram-se as práticas de cessão de útero, também chamada de gravidez por substituição.

\section{REPRODUÇÃO ASSISTIDA E GRAVIDEZ POR SUBSTITUIÇÃO}

A história do ser humano enquanto sociedade é permeada por aspectos inerentes à fertilidade humana, independentemente da cultura. É possível observar diversos relatos históricos na antiguidade, como por exemplo, contos bíblicos em que mulheres milagrosamente conseguiam engravidar.

\footnotetext{
${ }^{3}$ Trata-se de artigo que sintetiza a pesquisa realizada junto ao Programa de Iniciação Científica da Faculdade de Direito de Franca.
} 
Até meados do século XV, a mulher era "anulada” pela sociedade e qualquer problema relacionado à esterilidade ou infertilidade lhe era atribuído ${ }^{4}$. Observa-se, por exemplo, que na sociedade patriarcal, o papel da mulher era centrado na maternidade, sem qualquer autonomia. A sexualidade, em virtude da moral religiosa, era tão somente para procriação, afinal, os filhos representavam a continuidade da figura paterna para que o pai tivesse diversos sucessores e continuasse o nome da família por várias gerações.

Atualmente, em virtude da efetivação de uma sociedade democrática, é possível observar a manifestação e conscientização das mulheres no sentido de luta por seus direitos, em prol de alcançar independência e igualdade.

Além disso, a significação de família se alterou. Deve-se considerar todas as formas de constituição de entidade familiar, bem como protegê-las de forma igual.

No atual Código Civil Brasileiro de 2002 a família não é mais constituída unicamente pelo casamento. ${ }^{5}$ A Constituição de 1988 também amplia o conceito de família, que passa a significar "a comunidade formada por qualquer dos pais e seus descendentes"6, conforme relata Maria Berenice Dias:

A Constituição Federal de 1988 alargou o conceito de família, passando a integrá-lo às relações monoparentais, de um pai com os seus filhos. Esse redimensionamento, calcado na realidade que se impôs, acabou afastando da ideia de família o pressuposto de casamento. Para sua configuração, deixou-se de exigir a necessidade de existência de um par, o que, consequentemente, subtraiu de sua finalidade a proliferação. ${ }^{7}$

De acordo com o Código Civil, com a mudança da sociedade, reconhece o casamento civil, religioso, união estável ou comunidade na formação de unidades familiares, seja ela formada por mãe solteira, qualquer um dos pais ou os seus descentes. O conceito de família passou a

\footnotetext{
${ }^{4}$ FERRAZ, Ana Cláudia Brandão de Barros Correia. Reprodução Humana Assistida e suas consequências nas relações de família: a filiação e a origem genética sob a perspectiva da repersonalização. Curitiba. Juruá, 2011, p. 40.

${ }^{5}$ BRASIL. Código Civil, Lei 10.406, de 10 de janeiro de 2002. 1a edição. São Paulo: Revista dos Tribunais, 2002.

${ }^{6}$ BRASIL. Constituição (1988). Constituição da República Federativa do Brasil. São Paulo: Revista dos Tribunais, 2000.

${ }^{7}$ DIAS, Maria Berenice Manual de Direito das Famílias. $7^{\text {a }}$. ed. rev., atual e ampl. São Paulo: Revista dos Tribunais, 2010, p. 65.
} 
ser baseado mais no afeto do que apenas em relações de sangue, parentesco ou casamento.

O Direito Germânico, o Direito Canônico e o Direito Islâmico tinham como base da sociedade a família e a importância de ter filhos para continuação da mesma.

Entretanto, nem todas as pessoas conseguiam ter filhos, e isto, era motivo de divórcio no Direito Romano, pois a esterilidade era atribuída exclusivamente à mulher. No entanto, com o advento das técnicas de reprodução assistida isto mudou.

Bueno e Menezes afirmam que a primeira experiência relacionada às técnicas de reprodução humana no mundo se deu no século XVIII com John Hunter. Este inglês, utilizou-se da esposa de um comerciante para seu experimento. ${ }^{8}$

Historicamente, é possível observar que na época de guerra, especificamente no ano de 1945, registrou-se cerca de vinte e cinto mil nascimentos provenientes de inseminação artificial, em que a maioria deles era de soldados norte-americanos e de suas mulheres que com o receio do resultado da guerra, queriam garantir sua descendência. ${ }^{9}$

Em 1978, foi registrado na Inglaterra o nascimento da primeira bebê oriundo dessa tecnologia e ficou conhecida como Loiuse Brown. Com seu nascimento surgiram questões antes não debatidas com manipulação de gametas e embriões, estrutura celular e genética, entre outros.

Para se falar em gravidez por substituição, deve-se entender primeiramente do que se trata a reprodução assistida.

\footnotetext{
${ }^{8}$ BUENO, J. GERALDO R. e MENEZES, D. FRANCISCO N. Os limites da gestação de substituição na reprodução assistida, p. $20 . \quad$ Disponível em: http://www.egov.ufsc.br/portal/sites/default/files/os_limites_da_ gestacao_de_substituicao_na_reproducao.pdf Acesso em: 07/05/2018.

${ }^{9}$ QUEIROZ, Juliane Fernandes. Parentalidade: aspectos jurídicos e técnicas de inseminação artificial. Belo Horizonte. Del Rey. 2001, p. 73.
} 


\subsection{REPRODUÇÃO ASSISTIDA}

Reprodução assistida são técnicas utilizadas por médicos com o objetivo de criar a possibilidade de viabilização de gestação em casais com dificuldade ou com impossibilidade de engravidar.

As técnicas relacionadas à reprodução assistida surgiram com o intuito de superação às dificuldades inerentes à reprodução humana de forma natural. A partir do século XX, a ciência avançou no sentido de melhoramento da existência humana e dentre outras formas de experimentos, estão a reprodução in vitro, conhecida também como reprodução assistida. ${ }^{11}$

Fernandes assevera que "as técnicas de reprodução assistida são avanços biotecnológicos que tanto permitem contornar problemas de esterilidade, quanto solucionar alguns de infertilidade". ${ }^{12}$

Em síntese, para fins de estudo é necessário considerar a reprodução humana assistida como um tipo de tratamento médico, com manipulação de gametas, sendo estes espermatozoides ou óvulos, em laboratório com o fim de viabilidade gestacional.

As técnicas utilizadas por médicos especializados são determinadas de acordo com o tipo de infertilidade ou esterilidade apresentado.

$\mathrm{Na}$ Fecundação in vitro (FIV), uma das técnicas mais conhecidas, tanto o oócito, quanto o espermatozoide são retirados para serem analisados e posteriormente devolvidos com a consequente fertilização, de tal forma que o embrião desenvolvido será devolvido ao útero da mulher. 13

Outros conceitos importantes para entender o tema deste trabalho são as técnicas de reprodução assistida homóloga e heteróloga.

\footnotetext{
${ }^{10}$ UREL, Isadora, Técnicas de reprodução assistida: entre a medicina e o direito: as famílias do amanhã. Dissertação Mestrado. PUC-SP. São Paulo, 2017. p. 20.

${ }^{11}$ BUENO, J. GERALDO R. e MENEZES, D. FRANCISCO N. Os limites da gestação de substituição na reprodução assistida, p. 20. Disponível em: http://www.egov.ufsc.br/portal/sites/default/files/os_limites_da_gestacao_de_substituicao_na_reprod ucao.pdf Acesso em: 07/05/2018.

${ }^{12}$ FERNANDES, Tycho Brahe. A reprodução assistida em face da bioética e do biodireito: aspectos do direito de família e do direito das sucessões. Florianópolis: Diploma Legal, 2000, p. 52.

${ }^{13}$ UREL, Isadora, Técnicas de reprodução assistida: entre a medicina e o direito: as famílias do amanhã. Dissertação Mestrado. PUC-SP. São Paulo, 2017. p. 20/21.
} 
$\mathrm{Na}$ primeira, utiliza-se os oócitos e os espermatozoides do próprio casal, enquanto que na segunda, utilizam-se gametas de um desconhecido e um dos pais, ou de dois desconhecidos.

As técnicas que utilizam material genético do próprio casal trazem menores embates para o ordenamento jurídico, mas as que utilizam o material genético de terceiro devem ter as relações melhor analisadas.

Com o avanço dos estudos nessa área, a preocupação primordial era que fossem observados alguns princípios que regem a bioética, como o da autonomia, ou livre consentimento esclarecido, a beneficência e não maleficiência e a justiça, todos eles observando o princípio fundamental da dignidade da pessoa humana, assim como elenca Gouyon:

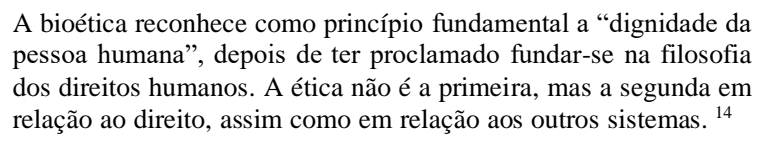

$\mathrm{Na}$ inseminação artificial heteróloga, o embate é maior ainda, haja vista que a gravidez ocorrerá utilizando-se de material de terceiro.

Com o avanço da engenharia genética, foi indispensável refletir acerca das implicações no ordenamento jurídico e no cotidiano.

\subsection{GRAVIDEZ POR SUBSTITUIÇÃO}

O atual Código Civil, em seu capítulo que trata do Direito de Filiação, deixou algumas lacunas no ordenamento jurídico ao tratar do tema em questão. Isto porque, a definição que se tem de maternidade relaciona o "ser mãe" com a gestação e com o parto.

A maternidade em si pode ocorrer tanto pelo parto, quanto por vínculos sócio afetivos.

Acerca da maternidade por substituição, Venosa traz o seguinte apontamento:

O embrião de um casal pode ser transferido para o útero de outra mulher, para possibilitar a gestação, impossível ou difícil na mãe biológica. Esse fenômeno traz à baila a questão ética, moral e

\footnotetext{
${ }^{14}$ GOUYON, Pierre Henri, et al. A Bioética é de má fè?: as leis Bioéticas, ou como mascarar os interesses contraditórios. São Paulo: Campanário / Loyola, 2005.
} 
jurídica das mães de aluguel ou mãe sub-rogada, conforme estas aceitem o encargo sob pagamento ou sob motivos altruístas. Essa matéria traz à baila a discussão sobre a declaração de maternidade ao lado da paternidade que a legislação também não contempla, colocando mais uma vez na berlinda o princípio mater est. Imposta saber, em cada caso, se houve o consentimento da mulher que cedeu o útero e se reconheceu a maternidade alheia. ${ }^{15}$

Atualmente, essa presunção relacionada ao princípio mater est (quanto à maternidade) não é adequada, tendo em vista que o conceito de família abrange diversas concepções muito mais amplas. A própria reprodução humana rompe com o paradigma da filiação que antigamente só ocorria através da relação sexual.

A gravidez por substituição ocorre quando a mãe não tem condições fisiológicas de desenvolver o embrião dentro do próprio útero, o que leva a ideia de que outra mãe o possa fazer, ou seja, a mãe substituta ou mãe portadora levará a gestação.

É possível ainda, que a mãe substituta faça a doação dos oócitos, caso a futura mãe também não tenha condições de produzi-los. ${ }^{16}$

No Brasil, desde o avanço da reprodução assistida, tendo em vista a escassa legislação relativa ao tema, a gravidez por substituição acaba por ser regulamentada, em seus aspectos gerais, por alguns dispositivos específicos da área de medicina, como a antiga Resolução de 2015 do Conselho Federal de Medicina, a qual previa, ad exemplum, a necessidade de que "doadora" do útero seja da família de um dos futuros pais em até quarto grau de parentesco consanguíneo, com idade limite de até 50 anos, e que o acordo não tenha caráter lucrativo.

O Código Civil não disciplina a cessão do útero, cabendo apenas aos Conselhos de Medicina normatizar e fiscalizar as atividades médicas, com a ressalva de que suas resoluções têm caráter ético.

Minahim aponta em sua obra A Família na Contemporaneidade: Aspectos Jurídicos quais os requisitos para a cessão do útero:

O empréstimo de útero pode ocorrer [...] de três situações[...]: impossibilidade de produção de óvulos e útero saudável; capacidade de produção de óvulos e ausência de útero ou lesão

\footnotetext{
${ }^{15}$ VENOSA, Silvio de Salvo. Direito Civil: Direito de família. 5. ed. $6^{\circ}$ Vol. São Paulo: Atlas, 2006. pp. 273-274.

${ }^{16}$ UREL, Isadora, Técnicas de reprodução assistida: entre a medicina e o direito: as famílias do amanhã. Dissertação Mestrado. PUC-SP. São Paulo, 2017. p. 21.
} 
uterina incompatível com a gestação; ou a cumulação das duas incapacidades. ${ }^{17}$

Oliveira aduz que a maternidade por substituição consiste em um contrato firmado entre as partes em que uma mulher concorda em gestar em seu útero uma criança, e do nascimento entregá-la renunciando o direito como consta no Código Civil de "ser mãe". ${ }^{18}$

Para evitar constrangimentos na hora de registrar o nascimento da criança, o Enunciado 129 da I Jornada de Direito Civil propõe que se inclua junto ao art. 1.597 do Código Civil fazendo menção ao registro especificamente no que tange a técnica de reprodução assistida heteróloga ${ }^{19}$,

O Conselho Nacional de Justiça (CNJ) publicou o Provimento n.52 dia 14 de março de 2016 onde estabelece que nos casos de gestação por substituição, não constará no registro o nome da mulher que realizou o parto. Embora o Provimento não seja claro quanto ao registro sair no nome de quem cedeu o óvulo, é a interpretação que se tem dado, a fim de evitar que se recorra ao Judiciário para discutir uma questão tão particular, utilizando-se, portanto, de critérios biológicos. ${ }^{20}$

Com a gravidez por substituição e as demais técnicas de reprodução assistida é possível observar um novo tipo de maternidade e paternidade, anteriormente não admitida pela sociedade e ainda não prevista na legislação.

Nesse sentido, explana Barboza:

Diante das técnicas de reprodução humana, estamos conhecendo um novo tipo de paternidade e maternidade, que revoluciona os princípios até então assentados pela tradição jurídica, a exigir um novo conceito ou a ampliação do já existente. Houve pelo menos em parte uma desbiologização da paternidade. Realmente os novos tempos estão a demonstrar a indispensabilidade de tratamento

\footnotetext{
${ }^{17}$ MINAHIM, Maria Auxiliadora. A Família na Contemporâneidade: Aspectos Jurídicos. Salvador: JusPodivm, 2007.pág. 17.

${ }^{18}$ OLIVEIRA, Guilherme, Mãe há só uma/duas!, Coimbra: Coimbra Editora, 1992, p. 9.

${ }^{19}$ I Jornada de Direito Civil, promovida pelo Centro de Estudos Judiciários (CEJ) do Conselho da Justiça Federal (CJF), nos dias. 12 e 13 de setembro de 2002, Brasília - DF. Disponível em: <http://www.cjf.jus.br/cjf /CEJ-Coedi/jornadas-cej/enunciados-aprovados-da-i-iii-iv-e-v-jornada-dedireito-civil/compilacaoenunciados aprovados1-3-4jornadadircivilnum.pdf >. Acesso em: 08 mai. 2018

${ }^{20}$ BRASIL. Conselho Nacional de Justiça. Corregedoria regulamenta registro de criança gerada por reprodução assistida. Disponível em: <http://www.cnj.jus.br/noticias/cnj/81780-corregedoriaregulamenta-registro-de-crianca-gerada -por-reproducao-assistida>. Acesso em: 07 mai. 2018.
} 
condigno ao tema paternidade-maternidade-filiação, mormente diante das técnicas de reprodução humana assistida. ${ }^{21}$

A fonte geradora do vínculo parental, diante dos casos envolvendo as técnicas de reprodução medicamente assistida, deixou de ser um fato natural (o ato sexual), passando a consistir na vontade e, consequentemente, no consenso, a abalar o arcabouço normativo no tema da paternidade, maternidade e filiação. ${ }^{22}$

Em suma, com o avanço da reprodução assistida, sugiram novas formas de procriação e de famílias. A gravidez por substituição é uma das soluções que as pessoas que não conseguem ter filhos podem recorrer para realizar o sonho da maternidade ou paternidade. Devem ser prestados esclarecimentos acerca do processo e as partes devem estar psicologicamente cientes. Ademais, no Brasil, a legislação sobre o tema é escassa e deve ser analisada.

Existem duas correntes no Brasil ao abordar o contrato de gravidez por substituição. A primeira, defendida por Maria Berenice Dias, afirma que o contrato é inválido por possuir como objeto uma criança, tornando a prática ilícita. ${ }^{23}$ Por outro lado, na segunda corrente defendida por autores como Mendes e Hryniewicz e Sauwen, predomina a ideia de que o objeto do contrato não é a criança, mas a "cessão" do útero da mulher, por isso, não aceitam a ideia de ter objeto ilícito pois não está em discussão o bebê e sim a decisão da mulher em ceder o útero a outrem. ${ }^{24}$

A Resolução n. 2.168/2017 do Conselho Federal de Medicina revogou a resolução anterior (Resolução 2.121/2015) e ampliou o rol de parentes que podem ceder o útero temporariamente para a gravidez por substituição.

Até 2015, somente as mulheres ascendentes da mulher e/ou homem da família poderiam doar o oócito, enquanto que com a Resolução

\footnotetext{
${ }^{21}$ BARBOZA, Heloísa Helena. A filiação em face da inseminação artificial e da fertilização "in vitro". Rio de Janeiro: Editora Renovar, 1993, p. 107

${ }^{22}$ GAMA, Guilherme Calmon Nogueira da. Filiação e Reprodução Assistida: Introdução ao tema sob a perspectiva do direito comparado. São Paulo: RT, n. 776, 2000, p. 73.

${ }^{23}$ DIAS, Maria Berenice. Manual de direito das famílias. 4. ed. rev., atual. e ampl. São Paulo: Revista dos Tribunais, 2007, p. 332

${ }^{24}$ HRYNIEWICZ, Severo; SAUWEN, Regina Fiuza. O direito "in vitro": da bioética ao biodireito. 3.ed. Rio de Janeiro: Lumen Juris, 2008.
} 
em vigor, descendentes também passaram a poder, como por exemplo, filhas e sobrinhas. Atualmente, dita Resolução também prevê a possibilidade de doação de material genético de terceiro, no entanto a análise deverá ser feita caso a caso perante o Conselho Federal de Medicina, que observará entre os requisitos, ausência de eventuais doadores na família.

Além disso, o item que trata sobre a gravidez por substituição teve sua terminologia alterada de "doação temporária do útero" para "cessão temporária do útero".

Anteriormente, só se previa a utilização desta técnica em últimos casos, como por exemplo, quando havia a existência de problema médico ou em casos de união homoafetiva. A Resolução de 2017 incluiu também a possibilidade de pessoas solteiras usarem a técnica da gravidez por substituição, antes liberada somente para casais.

Considerando que não há, no Brasil, legislação a respeito deste tema, faz-se analisar a legislação de Portugal para então entender de que forma podem ser utilizadas as Resoluções do Conselho Federal de Medicina para garantir maior segurança jurídica às partes que queiram se utilizar dessa técnica no Brasil.

\section{A RESILIÇÃO UNILATERAL NO CONTRATO DE GRAVIDEZ POR SUBSTITUIÇÃO EM PORTUGAL}

Em regra, em Portugal, o acordo de vontade é realizado entre as mulheres - a gestante e a mulher autora do projeto parental - no entanto, não se pode esquecer que há necessidade pela legislação deste país, da autorização, da ciência e da consentimento nos casos em que há a figura do marido ou companheiro(a) de ambas as partes.

Em Portugal, a questão da desistência, ou seja, da resilição unilateral contrato não é uma possibilidade e isso, na visão desta autora é algo repudiável, pois a gestante não tem direito à arrependimento. A gestante, por força do contrato é obrigada a entregar a criança logo após o nascimento.

No entanto, na prática essa desistência pode ocorrer, e como é a solução em Portugal? 
$\mathrm{O}$ artigo 81, n. ${ }^{\circ} 2$ do Código Civil português tem a seguinte redação "A limitação voluntária, quando legal, é sempre revogável, ainda que com obrigação de indemnizar os prejuízos causados às legítimas expectativas da outra parte", ou seja, as pessoas são livres para dispor de seus direitos da personalidade podendo portanto, desistir desse contrato. ${ }^{25}$

$\mathrm{Na}$ prática, essa questão acaba sendo resolvida pela jurisprudência nos tribunais.

Leva-se em conta, portanto, a questão da conforme a redação do artigo 817 do Código Civil português:

Não sendo a obrigação voluntariamente cumprida, tem o credor o direito de exigir judicialmente o seu cumprimento e de executar o património do devedor, nos termos declarados neste código e nas leis de processo. ${ }^{26}$

Marta Costa e Catarina Saraiva Lima a respeito da desistência traz as seguintes ponderações:

Neste sentido, cabe questionar se deverá ser concedido à portadora um período de reflexão para o arrependimento lícito (que não constitua, portanto, incumprimento), e se esta solução fará sentido ainda que a portadora não tenha qualquer relação genética com a criança; ou se, pelo contrário, a maternidade e/ou paternidade da criança deve encontrar-se já definida, imperativamente, no momento da celebração do contrato de maternidade de substituição, sem possibilidade de revogação posterior pelas partes envolvidas. $^{27}$

A título de exemplo, das perguntas realizadas no capítulo anterior, existe um caso emblemático que aconteceu em 1987, conhecido como "caso Baby M" em que William Stern e Elizabeth Stern firmaram contrato com Mary Beth Withehead para que esta cedesse o útero para gerar uma gravidez. Mary Beth passou pelo procedimento de inseminação in vitro com a inserção de espermatozoides de Willian. Quando a criança

\footnotetext{
${ }^{25}$ PORTUGAL. Lei 25/2016. Regula o acesso à gestação de substituição, procedendo à terceira alteração à Lei n. ${ }^{\circ}$ 32/2006, de 26 de julho (procriação medicamente assistida). Portugal, PT, 2016. ${ }^{26}$ PORTUGAL. Lei 25/2016. Regula o acesso à gestação de substituição, procedendo à terceira alteração à Lei n. ${ }^{\circ}$ 32/2006, de 26 de julho (procriação medicamente assistida). Portugal, PT, 2016.

${ }^{27}$ COSTA, Marta e LIMA, Catarina Saraiva.A Maternidade de Substituição à luz dos direitos fundamentais de personalidade. In Lusíada. Direito. n. ${ }^{\circ}$ 10. 2014. p. 284.
} 
nasceu, Mary Beth se recusou a entregar a criança. Com isso, o casal ajuizou ação contra Mary Beth para que o contrato fosse cumprido. ${ }^{28}$

Na primeira instância, o casal teve seu pedido deferido, com sentença de procedência para que que Mary Beth entregasse ao casal a criança. No entanto, a Suprema Corte de Nova Jersey, reformou a decisão e embora a custódia ficasse com William, com vista a questão biológica, Mary Beth passou a ter direito de visita e convivência. ${ }^{29}$

Claramente, esta questão da resilição unilateral do contrato é extremamente complexa e contraditória sendo possível imaginar infinitas hipóteses para solução justamente por ter várias hipóteses do uso da técnica de acordo com a autoridade do material genético, no entanto, nenhuma delas prevista na legislação, ficando a cargo de juízes decidirem.

Omaida Patrícia da Cruz Van-Dúnem traz algumas soluções com base na propriedade do material genético. Vejamos:

Quando o material genético pertencer aos dois autores do projeto parental, sendo a gestante apenas "portadora", ou seja, não há material genético da gestante na relação, nesse caso, aplicar-se-ia o artigo 1796 n $^{\circ}$ 2 que fala que "a paternidade presume-se em relação ao marido da mãe e, nos casos de filiação fora do casamento, estabelece-se pelo reconhecimento", já que não há elementos biológicos, então não se utilizaria o parto como pressuposto de filiação. ${ }^{30}$

Quando o material genético for do casal autor do projeto parental e a criança nascer com alguma deficiência física ou neurológica, não há possibilidade de arrependimento, considerando a propriedade do material genético, da mesma forma do parágrafo anterior. ${ }^{31}$

Da mesma forma, nos casos em que o óvulo fecundado pertence à gestante, deve-se aplicar o artigo 1796 n. 2 primeira parte, do Código

\footnotetext{
${ }^{28}$ FUCHS, Erin. This Nasty Court Case Halped Make Surragacy Illegal In New York. Business Insider, Nova York, 2014. Disponível em: https://www.businessinsider.com/the-case-of-baby-m-2014-2. Acesso em 14 de julho de 2019.

${ }^{29}$ FUCHS, Erin. This Nasty Court Case Halped Make Surragacy Illegal In New York. Business Insider, Nova York, 2014. Disponível em: https://www.businessinsider.com/the-case-of-baby-m-2014-2. Acesso em 14 de julho de 2019.

${ }^{30}$ VAN-DÚNEM, Omaida Patrícia da Cruz. Maternidade de substituição: Solução e/ou Problema? Para uma abordagem no âmbito de Direito de Família. 2018. Dissertação (Mestrado em Direito) Universidade Autonoma de Lisboa, Lisboa, 2018.p. 76

${ }^{31}$ Ibid. p. 76
} 
Civil português, tendo em vista que neste caso há ligação biológica entre a gestante e o nascituro. ${ }^{32}$

Quando não há nenhum material genético dos autores do projeto parental, também deve aplicar o artigo mencionado nos parágrafos anteriores. ${ }^{33}$

Vera Lúcia Raposo sabiamente aborda o direito ao arrependimento como sendo uma das matérias com mais contradições no que diz respeito aos contratos de gravidez por substituição. Isto porque, se arrepender, desistir, resilir o contrato unilateralmente é preservar a liberdade da mulher decidir sobre seu corpo, sendo que essa liberdade fica limitada por um contrato. ${ }^{34}$

Para análise, didaticamente fica mais fácil pensar separado os casos de resilição por desistência ou arrependimento:

1. A mãe que cedeu o útero pode se recursar a fazer a inseminação ou então pode abortar o embrião no prazo determinado pelo contrato. Após o parto, a mulher pode se recusar a entregar o bebê por ter criado laços de afeto.

2. Os autores do projeto parental se arrependerem de ter a criança, recusando em ficar com ela para si após o nascimento ou requerendo a gestante que aborte.

Em nenhum dos casos que surgirem a questão da desistência, ou do arrependimento fica claro como seriam os encargos, ou então as questões da responsabilidade civil.

Vera Lúcia Raposo afirma que:

Nos casos de arrependimento, em que há necessidade da sua solução ser encontrada num tribunal, penso que não deverá ser decidido sob o domínio do Direito das Obrigações mas sim sob o domínio do Direito da Família. ${ }^{35}$

Tal entendimento é justamente visando o melhor interesse da criança e não somente sob a vertente de que esta seria mero objeto contratual.

\footnotetext{
${ }^{32}$ Ibid. p 76

${ }^{33}$ Ibid. p. 76

${ }^{34}$ RAPOSO, Vera Lúcia. Tudo aquilo que você sempre quis saber sobre os contratos de gestação (mas o legislador teve medo de responder). In Revista do Ministério Público. N. ${ }^{\circ} 149$, ano 38, 2017. p. 18.

${ }^{35}$ RAPOSO, Vera Lúcia e PEREIRA, André. Primeiras Notas Sobre a Lei Portuguesa da Procriação Medicamente Assistida (Lei n. ${ }^{\circ}$ 32/2006, de 26 de julho). In Lex Medicinae. Ano 3, n. ${ }^{\circ}$ 6, 2006
} 
Omaida Patrícia da Cruz Van-Dúnem entende, portanto, que a desistência, o arrependimento, a resilição unilateral de tal contrato só podem ocorrer até a transferência uterina. ${ }^{36}$

Para Vera Lúcia Raposo no caso de resilição unilateral do contrato, após o nascimento seria: é “(...) a única hipótese destes contratantes se «desligarem» da criança é entregá-la para a adoção, pois não existe outra forma de «escapar» da parentalidade, nem mesmo uma hipotética cedência da criança à gestante de substituição, a qual apenas poderá manter a criança consigo por via de uma futura adoção.”37

Tal redação, através da leitura da Lei 15/2016 e do contrato do CNPMA utilizado em Portugal parece ser adequada, tendo em vista que o contrato deixa claro a questão da filiação e deve-se cumprir o contrato em caso de eventuais desentendimentos.

No máximo, poderão as partes que se sentirem lesadas pela resilição unilateral entrarem com ação no tribunal para discutir indenização e responsabilidade civil, visto que nesse ponto a lei e o contrato são completamente omissos e considerando que foram informados dos riscos e demais implicações éticas, jurídicas e sociais.

\subsection{ANÁLISE DO CONTRATO DE GRAVIDEZ POR SUBSTITUIÇÃO NO BRASIL E SEUS DESDOBRAMENTOS JURÍDICOS.}

A resilição é uma das formas de extinção do contrato por vontade de uma das partes e embora seja o contrato seja regido pelo princípio da obrigatoriedade (quando firmado deve ser cumprido para garantir segurança jurídica), este princípio não é absoluto.

No caso da gravidez por substituição deve ser analisada de forma separada para entender a viabilidade. Primeiramente será analisada do ponto de vista da gestante de substituição rescindir o contrato.

\footnotetext{
${ }^{36}$ VAN-DÚNEM, Omaida Patrícia da Cruz. Maternidade de substituição: Solução e/ou Problema? Para uma abordagem no âmbito de Direito de Família. 2018. Dissertação (Mestrado em Direito) Universidade Autonoma de Lisboa, Lisboa, 2018.

${ }^{37}$ RAPOSO, Vera Lúcia e PEREIRA, André. Primeiras Notas Sobre a Lei Portuguesa da Procriação Medicamente Assistida (Lei n. ${ }^{\circ}$ 32/2006, de 26 de julho). In Lex Medicinae. Ano 3, n. ${ }^{\circ}$ 6, 2006.
} 
A gestante de substituição pode rescindir o contrato antes do processo de reprodução assistida, ou seja, no que seria chamado de "fase pré-contratual” o que não traria implicação para nenhuma das partes.

Durante a gravidez em si, considerando o sistema Penal Brasileiro e também tópico desse trabalho, a gestante de substituição no Brasil não poderia interromper a gravidez pois se enquadraria no crime de aborto tipificado no artigo $124 .{ }^{38}$

Após o nascimento com vida é a questão que traz confusão para o ordenamento jurídico, pois resilição unilateral implica na recusa da mãe de substituição entregar o bebe ao autor do projeto parental.

Depois de ter feito a análise sobre o contrato utilizado em Portugal, parece para esta autora, que deve ser seguido o que consta no contrato a respeito da filiação, ou seja, se o material genético utilizado foi o da mãe de substituição, a resilição unilateral sendo desta, "não haveria problema" no que diz respeito a não entrega do recém-nascido. No entanto, se o material genético utilizado foi do(s) autor(es) do projeto parental, o correto, seguindo a linha do contrato de substituição de Portugal seria a obrigatoriedade na entrega do recém-nascido a estes.

A problemática maior surge quando o material genético utilizado é de doador anônimo, que nem sabe da existência da gravidez por substituição e tampouco tem interesse no recém-nascido. Neste caso, o que parece ser mais prudente é seguir o contrato quanto à determinação da filiação, ou seja, que o recém-nascido é filho do(s) autor(es) do projeto parental, pois não daria para deixar para que o judiciário analise caso a caso, do contrário, não analisar a filiação presente no contrato traria extrema insegurança jurídica.

Esgotada as hipóteses de resilição unilateral por parte da mãe de substituição, deve-se analisar a mesma atitude por parte dos autores do projeto parental. O que ocorre se os autores do projeto parental decidirem resilir o contrato?

Da mesma forma que abordado anteriormente, caso o contrato seja resilido antes da do início do processo de reprodução assistida, deve ser tratado como fase pré-contratual e desta forma não há implicação para nenhuma das partes.

\footnotetext{
${ }^{38}$ BRASIL. Decreto-Lei 2.848, de 07 de dezembro de 1940. Código Penal. Diário Oficial da União, Rio de Janeiro, 31 dez. 1940.
} 
Caso os autores do projeto parental queiram que a gestante de substituição aborte, tal atitude é tipificada no Brasil como crime, então não seria permitida a resilição unilateral do contrato em hipótese alguma durante a gestação, após o uso da técnica de reprodução assistida e a implantação do óvulo.

A complicação também se dá após o nascimento da criança. Caso os alotes do projeto parental se recusem a receber a criança, considerando que no contrato deve estar previsto a filiação, parece que o não recebimento da criança se enquadraria na conduta tipificada no Código Penal como abandono de incapaz, do artigo 133: "Abandonar pessoa que está sob seu cuidado, guarda, vigilância ou autoridade, e, por qualquer motivo, incapaz de defender-se dos riscos resultantes do abandono", ou então como abandono de recém-nascido do artigo 134: "Expor ou abandonar recém-nascido, para ocultar desonra própria". 39

Para que os conflitos sejam resolvidos de forma mais pacífica, foi elaborado um contrato que eventualmente poderia ser utilizado no Brasil, com base no contrato existente em Portugal, visto que o que se usa atualmente no Brasil é o Termo de Consentimento das clínicas de reprodução assistida.

Em suma, é possível perceber que as questões de resilição unilateral do contrato podem possivelmente ser baseadas e resolvidas em torno da filiação que constar no contrato de gravidez por substituição.

\section{CONSIDERAÇÕES FINAIS}

Ao deslanche dessa pesquisa é possível perceber que houve um enorme avanço em relação às técnicas de reprodução assistida e com isso, houveram mudanças significativas em relação às configurações de família, no entanto, a legislação não acompanhou essa situação e há diversas lacunas no ordenamento jurídico frente ao tema gravidez por substituição.

Foi possível ter conhecimento através dessa monografia que a gravidez por substituição será utilizada como última opção, em casos de exceções médicas.

\footnotetext{
${ }^{39}$ BRASIL. Decreto-Lei 2.848, de 07 de dezembro de 1940. Código Penal. Diário Oficial da União, Rio de Janeiro, 31 dez. 1940.
} 
A Constituição Federal de 1988, em seu artigo $1^{\circ}$, inciso III tem a previsão do princípio da dignidade da pessoa humana, em que prevê que as pessoas devem ser respeitadas e tuteladas, tanto física quanto moralmente.

Além disso, o princípio do melhor interesse da criança, ainda que não previsto de forma expressa em nenhuma legislação, embasam as questões de filiação e de registro civil, pois é fundamental observar quem foram os autores do projeto parental e idealizaram o nascimento da criança, que frisa a importância dos laços afetivos em detrimento do laço biológico.

Ante à complexidade e a relevância da prática da gravidez por substituição, mostra-se indispensável que o Brasil tenha uma lei que regulamente de forma devida a questão, que se apresenta tão controvertida.

Tendo em vista tais questões, o presente trabalho analisou a importância do desenvolvimento de regulamentação sobre a gravidez por substituição no ordenamento jurídico brasileiro, bem como a aplicação da legislação já existente, e levantou questões bem como se preocupou em resolver os reflexos práticos no caso de resilição unilateral do contrato de gravidez por substituição observando então a mais recente Resolução do Conselho Federal de Medicina, e os projetos de lei que tramitam na Câmara, os princípios constitucionais envolvidos, entre outros aspectos dogmáticos relativos à gravidez por substituição.

Para aprofundamento da questão da resilição unilateral foi analisada a legislação acerca da "procriação medicamente assistida" e a gravidez por substituição de Portugal e também foi elaborado contrato que eventualmente poderia ser utilizado com base na legislação brasileira para garantir maior segurança jurídica.

É notável a importância do estudo acerca da gravidez por substituição, haja vista que no Brasil, a única posição consolidada se dá por meio de Resolução do Conselho Federal de Medicina (Resolução $n^{\circ}$ 2.168/2017) que disciplina que uso da técnica. Evidentemente essa resolução por si só não é suficiente para regular todas as questões que este tema gera, visto que as normas do Conselho Federal de Medicina tem eficácia somente em relação aos médicos, o que tão somente já reflete a necessidade de uma legislação consolidada no Brasil.

Não se pode ignorar que com o debate e a regulamentação da reprodução assistida, recurso este que favorece a fecundação humana, surge a prerrogativa de que também poderá, a gravidez por substituição, ter uma regulamentação no ordenamento jurídico brasileiro, assim como já 
existe em outros países. Por esta autora acreditar que a técnica da gravidez por substituição ser consequência da evolução da reprodução humana assistida, este trabalho foi realizado na perspectiva de que é necessário a legalização e a regulamentação acerca do tema.

Outrossim, este tema, demonstra-se ainda extremamente controverso, visto que há pouca discussão desenvolvida acerca da possibilidade de regulamentação no país, e há uma lacuna legislativa. $\mathrm{O}$ tema é bastante complexo pois passa a englobar o direito em diversas esferas como dos princípios constitucionais, de família, das sucessões, das obrigações, da bioética, da personalidade, no campo penal, entre outros.

\section{REFERÊNCIAS BIBLIOGRÁFICAS}

BARBOZA, Heloísa Helena. A filiação em face da inseminação artificial e da fertilização "in vitro". Rio de Janeiro: Editora Renovar, 1993, p. 107

BRASIL. Constituição (1988). Constituição da República Federativa do Brasil. São Paulo: Revista dos Tribunais, 2000.

. Conselho Nacional de Justiça. Corregedoria regulamenta registro de criança gerada por reprodução assistida. Disponível em:

$<$ http://www.cnj.jus.br/noticias/cnj/81780-corregedoria-regulamenta-registro-de-criancagerada -por-reproducao-assistida>. Acesso em: 07 mai. 2018.

. Decreto-Lei 2.848, de 07 de dezembro de 1940. Código Penal. Diário Oficial da União, Rio de Janeiro, 31 dez. 1940.

Código Civil, Lei 10.406, de 10 de janeiro de 2002. 1a edição.

São Paulo: Revista dos Tribunais, 2002.

BUENO, J. GERALDO R. e MENEZES, D. FRANCISCO N. Os limites da gestação de substituição na reprodução assistida, p. 20. Disponível em:

http://www.egov.ufsc.br/portal/sites/default/files/os_limites_da_gestacao_de_substituicao _na_reproducao.pdf Acesso em: 07/05/2018.

COSTA, Marta e LIMA, Catarina Saraiva.A Maternidade de Substituição à luz dos direitos fundamentais de personalidade. In Lusíada. Direito. n. ${ }^{\circ} 10.2014$.

DIAS, Maria Berenice. Manual de direito das famílias. 4. ed. rev., atual. e ampl. São Paulo: Revista dos Tribunais, 2007. 
dos Tribunais, 2010.

FERNANDES, Tycho Brahe. A reprodução assistida em face da bioética e do biodireito: aspectos do direito de família e do direito das sucessões. Florianópolis: Diploma Legal, 2000 .

FERRAZ, Ana Cláudia Brandão de Barros Correia. Reprodução Humana Assistida e suas consequências nas relações de família: a filiação e a origem genética sob a perspectiva da repersonalização. Curitiba. Juruá, 2011.

FUCHS, Erin. This Nasty Court Case Halped Make Surragacy Illegal In New York. Business Insider, Nova York, 2014. Disponível em: https://www.businessinsider.com/thecase-of-baby-m-2014-2. Acesso em 14 de julho de 2019.

GAMA, Guilherme Calmon Nogueira da. Filiação e Reprodução Assistida: Introdução ao tema sob a perspectiva do direito comparado. São Paulo: RT, n. 776, 2000.

GOUYON, Pierre Henri, et al. A Bioética é de má fè?: as leis Bioéticas, ou como mascarar os interesses contraditórios. São Paulo: Campanário / Loyola, 2005.

HRYNIEWICZ, Severo; SAUWEN, Regina Fiuza. O direito "in vitro": da bioética ao biodireito. 3.ed. Rio de Janeiro: Lumen Juris, 2008.

I Jornada de Direito Civil, promovida pelo Centro de Estudos Judiciários (CEJ) do Conselho da Justiça Federal (CJF), nos dias. 12 e 13 de setembro de 2002, Brasília - DF. Disponível em: <http://www.cjf.jus.br/cjf /CEJ-Coedi/jornadas-cej/enunciados-aprovadosda-i-iii-iv-e-v-jornada-de-direito-civil/compilacaoenunciados aprovados1-34jornadadircivilnum.pdf >. Acesso em: 08 mai. 2018

MINAHIM, Maria Auxiliadora. A Família na Contemporâneidade: Aspectos Jurídicos. Salvador: JusPodivm, 2007.

OLIVEIRA, Guilherme, Mãe há só uma/duas!, Coimbra: Coimbra Editora, 1992.

PORTUGAL. Lei 25/2016. Regula o acesso à gestação de substituição, procedendo à terceira alteração à Lei n. ${ }^{\circ} 32 / 2006$, de 26 de julho (procriação medicamente assistida). Portugal, PT, 2016.

QUEIROZ, Juliane Fernandes. Parentalidade: aspectos jurídicos e técnicas de inseminação artificial. Belo Horizonte. Del Rey. 2001.

RAPOSO, Vera Lúcia e PEREIRA, André. Primeiras Notas Sobre a Lei Portuguesa da Procriação Medicamente Assistida (Lei n. ${ }^{\circ}$ 32/2006, de 26 de julho). In Lex Medicinae. Ano 3, n. ${ }^{\circ}$ 6, 2006 
RAPOSO, Vera Lúcia. Tudo aquilo que você sempre quis saber sobre os contratos de gestação (mas o legislador teve medo de responder). In Revista do Ministério Público. N. ${ }^{\circ}$ 149, ano 38, 2017.

UREL, Isadora, Técnicas de reprodução assistida: entre a medicina e o direito: as famílias do amanhã. Dissertação Mestrado. PUC-SP. São Paulo, 2017.

VAN-DÚNEM, Omaida Patrícia da Cruz. Maternidade de substituição: Solução e/ou Problema? Para uma abordagem no âmbito de Direito de Família. 2018. Dissertação (Mestrado em Direito) - Universidade Autonoma de Lisboa, Lisboa, 2018.

VENOSA, Silvio de Salvo. Direito Civil: Direito de família. 5. ed. $6^{\circ}$ Vol. São Paulo: Atlas, 2006. 